\title{
PEMANFAATAN KEMBALI SAMPAH NON ORGANIK UNTUK MENCIPTAKAN LINGKUNGAN BERSIH DI FKIP UDA MEDAN
}

\author{
Oleh: \\ Jelita Panjaitan ${ }^{1)}$, Debi Iranti Siahaan ${ }^{2)}$, Rika Daya ${ }^{3)}$, Atustinus Giawa ${ }^{4)}$, \\ Arna Dewi Setia Halawa ${ }^{5)}$, Krisdayanti Hulu ${ }^{6}$ \\ Universitas Darma Agung, Medan ${ }^{1,2,3,4,5,6)}$ \\ E-mail : \\ jelitapanjaitan3@gmail.com ${ }^{1)}$, debbisiahaan@gmail.com ${ }^{2)}$, udarika891@gmail.com $^{3)}$, \\ $\underline{\text { atustinusgiawa@gmail.com }}^{4)}$, arnadewisetiah@gmail.com $^{5)}, \underline{\text { krisdayantihulu@gmail.com }}^{6)}$
}

\begin{abstract}
Research on mineral bottle waste aims at providing an example to all students of FKIP UDA (Faculty of Teacher Training and Education), regarding the utilization of plastic jug waste into useful and worthy goods. This study is to minimize the risk of plastic waste because plastic has non-biodegradable properties and takes a long time to decompose naturally in the soil. The merchandise to a chance to be made need aid handicrafts in the type of plastic junk jars (ToSaPlas). The implementations of activities are using the method of observation, practicum and documentation. Observations were filled by directly observing the research location and collecting plastic bottle waste, followed by making a proposal which included training materials for the manufacture of ToSaPlas including the preparation of raw materials for tools and supporting materials. The useful system is conveyed out toward the group In those duration of the time of making ToSaPlas until it may be completed. Then the documentation method was conveyed crazy throughout perception and practicum as evidence that the research was carried out well. The output target of this research is to increase student awareness of the faculty environment, while for partners this activity is a forum for discussion in developing creative ideas in the field of recycling plastic waste and making business products that can be offered in the market.
\end{abstract}

Keywords: Waste, Plastics, ToSaPlas

\section{ABSTRAK}

Penelitian terhadap sampah botol mineral bertujuan untuk memberikan contoh kepada seluruh mahasiswa FKIP UDA, tentang pemanfaatan sampah botol plastik menciptakan barang yang berguna dan layak pakai. Tujuannya adalah untuk meminimalkan risiko sampah plastik, karena plastik tidak terurai dan membutuhkan waktu lama untuk terurai secara alami ke dalam tanah. Barang yang akan dibuat adalah kerajinan tangan berbentuk tong sampah plastik (ToSaPlas). Pelaksanaan kegiatan menggunakan metode observasi, praktikum dan dokumentasi. Observasi diisi dengan meninjau secara langsung lokasi penelitian serta pengumpulan limbah botol plastik kemudian dilanjut dengan pembuatan proposal yang mencakup Materi edukasi untuk produksi ToSaPlas termasuk siapkan bahan baku, alat, dan bahan penolong. Metode praktikum dilaksanakan oleh tim pada saat pembuatan ToSaPlas hingga jadi. Kemudian metode dokumentasi dilaksanakan pada saat observasi dan praktikum 
sebagai bukti penelitian dilakukan dengan baik. Target luaran dalam studi ini adalah meningkatkan kepedulian mahasiswa terhadap lingkungan fakultas, Bagi mitra, kegiatan ini merupakan wadah untuk mengembangkan ide-ide kreatif di bidang daur ulang sampah plastik dan menciptakan produk bisnis yang bisa dibawa ke pasar.

\section{Kata Kunci: Sampah, Plastik, ToSAPlas}

\section{PENDAHULUAN}

Plastik tidak dapat terurai secara hayati dan membutuhkan waktu lama untuk terurai secara alami di dalam tanah. Jika tidak dikelola dengan baik dan benar, keberadaan sampah plastik dalam jumlah besar akan menimbulkan gangguan dan dampak terhadap lingkungan, baik yang mempengaruhi faktor fisik maupun kimia (kualitas air dan udara), biologi, sosial ekonomi, budaya dan sanitasi lingkungan. Pemerintah juga menghimbau kepada masyarakat untuk menghemat penggunaan plastik. Sebagai bagian dari upaya untuk mengatasi masalah limbah plastik tersebut, pemerintah membutuhkan kesadaran masyarakat akan pelaksanaan pengelolaan sampah dan peran serta masyarakat dalam perlindungan lingkungan adalah tanggung jawab bersama.

Pengelolaan sampah menurut UU Nomor 18 Tahun 2008 ini didefinisikan sebagai kegiatan yang sistematis, komprehensif dan berkelanjutan, termasuk pengurangan dan pembuangan limbah. Pemanfaatan kembali sampah adalah kegiatan untuk mengurangi jumlah sampah dengan tetap memanfaatkan nilai yang terkandung dalam sampah itu sendiri (air daur ulang, produk lain dan energi).

Upaya melakukan pemanfaatan kembali sampah diperlukan peran serta dari semua pihak, baik masyarakat maupun pemerintah. Namun, hingga saat ini pemanfaatan kembali sampah belum dilaksanakan secara optimal. Masih banyak masyarakat menganggap sepele terhadap sampah dan membuang sampah dengan sengaja.

Tentang kasus ini di masyarakat, maka masyarakat dirasa perlu untuk mendapat pengetahuan dan memahami pemanfaatan sampah plastik dalam mengurangi dampak dari permasalahan yang ditimbulkan oleh sampah itu sendiri. Penanganan yang dapat dilakukan sampah tidak digunakan sebagai sampah yang tidak berguna seperti kerajinan tangan, tetapi diperlakukan sebagai barang yang layak untuk digunakan kembali. Kerajinan tangan yang bisa dibuat adalah tong sampah plastik asli (ToSAPlas).

\section{TINJAUAN PUSTAKA}

Menurut Kodoatic (2003), Sampah adalah sampah padat atau setengah padat yang dihasilkan dari kegiatan manusia, hewan, tumbuhan atau perkotaan.Menurut Azwar (1990) menerangkan dalam bukunya bahwa Sampah harus dibuang jika tidak digunakan, digunakan atau disukai.

Menurut Undang-Undang RI Nomor 18 Tahun 2008 tentang Pengelolaan Sampah, Sampah merupakan sisa kegiatan manusia sehari-hari dan proses alam, serta berbentuk padat. Yang dimaksud dengan limbah spesifik berikut adalah limbah yang memerlukan penanganan khusus karena sifat, konsentrasi, atau kuantitasnya.

Pengelolaan sampah adalah segala kegiatan yang dilakukan untuk mengolah sampah mulai dari dihasilkan hingga pengolahan akhir. Secara umum kegiatan 
pengelolaan sampah meliputi pengendalian timbulan sampah, pengumpulan sampah, pengangkutan sebelumnya, pengolahan, dan pengolahan akhir. (Yudhi, 2009:9).

Secara umum, pengelolaan sampah di perkotaan dilakukan melalui tiga tahapan kegiatan yaitu pengumpulan, pengangkutan, dan pembuangan akhir, dan proses kegiatan pengelolaan sampah dapat diringkas sebagai berikut.

Pengumpulan didefinisikan dengan mengelola sampah, dari tempat timbulan sampah ke tempat pembuangan sementara, sebelum melanjutkan ke langkah berikutnya. Pada tahap ini digunakan fasilitas penunjang berupa tong sampah, tong sampah, tong sampah, gerobak, tempat sampah sementara, dan sebagainya.

Tahap pengangkutan dilakukan ke tempat pembuangan akhir/pembuangan akhir dengan menggunakan fasilitas pendukung berupa alat angkut khusus. Tahap ini juga mencakup personel untuk mengangkut limbah dari lokasi sementara ke tempat penyimpanan akhir selama periode waktu tertentu.

Pada tahap pembuangan akhir, limbah dilakukan pengolahan fisik, kimia dan biologi untuk menyelesaikan keseluruhan proses.

Kebersihan lingkungan mengacu pada tidak adanya kontaminan seperti debu, sampah, dan bau. Kebersihan merupakan upaya manusia untuk melindungi diri sendiri dan lingkungan dari hal-hal yang kotor maupun vulgar dalam rangka mewujudkan dan memelihara kehidupan yang sehat dan nyaman. Kebersihan merupakan syarat untuk mewujudkan kesehatan, dan kesehatan merupakan salah satu faktor yang dapat mendatangkan kebahagiaan. Sementara itu, noda tidak hanya merusak kecantikan, tetapi juga dapat menyebabkan berbagai penyakit, dan penyakit adalah salah satu penyebab penderitaan.

Lingkungan bersih ialah Lingkungan yang bersih bebas dari debu, kotoran dan bau.

\section{METODE PELAKSANAAN}

Pelaksanaan kegiatan ini dengan menggunakan metode: observasi, praktikum dan dokumentasi. Observasi dilaksanakan pada saat melakukan pengamatan tentang sampah yang ada di lingkungan FKIP UDA Medan. Praktikum dilaksanakan pada saat pembuatan ToSaPlas sebagai wujud nyata pemanfaatan kembali sampah non organik. Dokumentasi dilaksanakan pada saat melakukan pengamatan di lokasi, pembuatan ToSaPlas, penyerahan ToSaPlas untuk diletakkan di lingkungan FKIP sebagai bukti penelitian dilakukan dengan baik.

Pelaksanaan kegiatan ada dua langkah untuk penelitian ini, yaitu :

\section{Tahap Persiapan}

Sebelum kegiatan dilakukan, tim pelaksana melakukan koordinasi dengan semua anggota dan kemudian melakukan observasi ke lokasi mitra. Setelah itu melakukan koordinasi dengan pihak mitra untuk jadwal pelaksanaan kegiatan. Tahap persiapan juga meliputi persiapan materi kegiatan.

\section{Tahap Pelaksanaan}

Tahap pelaksanaan kegiatan penelitian ini dibagi menjadi dua sesi, yaitu

\section{a. Sesi Pertama}

Sesi pertama adalah mengobservasi sampah di FKIP UDA untuk dikumpulkan yang dilaksanakan oleh ketua kelompok beserta anggota. 
b. Sesi Kedua

Sesi kedua adalah praktikum pembuatan ToSaPlas, setelah sampah botol mineral terkumpul, ketua dan anggota kelompok bekerja sama dalam menyediakan alat dan bahan yang dibutuhkan, mengerjakan setiap langkah-langkah pembuatan dengan benar hingga terbentuk ToSaPlas.

Cara Pembuatan ToSaPlas meliputi:

a) Sediakan alat dan bahan

b) Lepaskan label merk pada botol mineral

c) Sediakan benda untuk membuat pola ToSaPlas, kemudian sambungkan alat lem tembak ke listrik dan tempelkan satu botol ke botol yang lain hingga membentuk tingkat pertama

d) Untuk membentuk tingkat kedua dilakukan dengan merekatkan botol mineral satu persatu di atas tingkat pertama sampai terbentuk pola yang sama di tingkat kedua

e) Potong-potong kawat besar dan kawat kecil sesuai kebutuhan, yang akan digunakan untuk merekatkan tiap-tiap pola agar tingkat satu dan tingkat kedua semakin erat pada bagian dalam dan luar pola

f) Untuk membentuk tingkat ketiga dilakukan dengan merekatkan botol mineral satu persatu di atas tingkat kedua sampai terbentuk pola yang sama di tingkat ketiga

g) Eratkan juga tingkat ketiga menggunakan kawat besar dan kawat kecil pada bagian dalam dan luarnya

h) Untuk membuat ToSaPlas yang lain maka lakukan kembali langkah-langkah dari poin a - poin $g$

i) Setelah ToSaPlas dieratkan dalam semua bagian, selanjutnya adalah mengeratkan dari atas ke bawah (tingkat pertama ke tingkat ketiga) menggunakan kawat besar agar semakin kuat

j) Kemudian masukkan karung goni ke dalam ToSaPlas mengikuti bentuknya untuk dijadikan alas, lalu di eratkan menggunakan kawat besar agar tidak mudah lepas

k) Cat ToSaPlas menggunakan pilox

\section{HASIL DAN PEMBAHASAN}

Kegiatan penelitian ini meliputi dua tahap, yaitu tahap persiapan dan tahap pelaksanaan. Tahap persiapan meliputi penyusunan proposal dialog antara ketua dan anggota tim peneliti, dan penetapan rencana kegiatan persiapan administrasi observasi lapangan. Hasil observasi dilaksanakan oleh kelompok penelitian dan memilih FKIP UDA Medan sebagai tempat kegiatan penelitian, kemudian dilanjutkan dengan koordinasi dengan pimpinan fakultas untuk perizinan pelaksanaan penelitian. Persiapan penelitian dilanjutkan setelah memperoleh izin dari mitra, kemudian kegiatan dilanjutkan dengan tahap pelaksanaan.

Tahap Pelaksanaan terdiri dari 2 sesi yaitu, sesi pertama adalah mengobservasi sampah di FKIP UDA untuk dikumpulkan, ketua kelompok beserta anggota melakukan observasi sampah botol mineral di lingkungan FKIP UDA, dikarenakan sampah botol mineral tidak bisa dikumpulkan hanya dalam sehari maka kelompok peneliti melakukannya secara berlanjut mulai dari awal bulan mei sampai tanggal 22 mei hingga akhirnya sampah botol mineral terkumpul untuk membuat ToSaPlas, dokumentasi dilakukan dalam sesi ini. Seperti ditunjukkan pada gambar 1 dibawah ini ; 


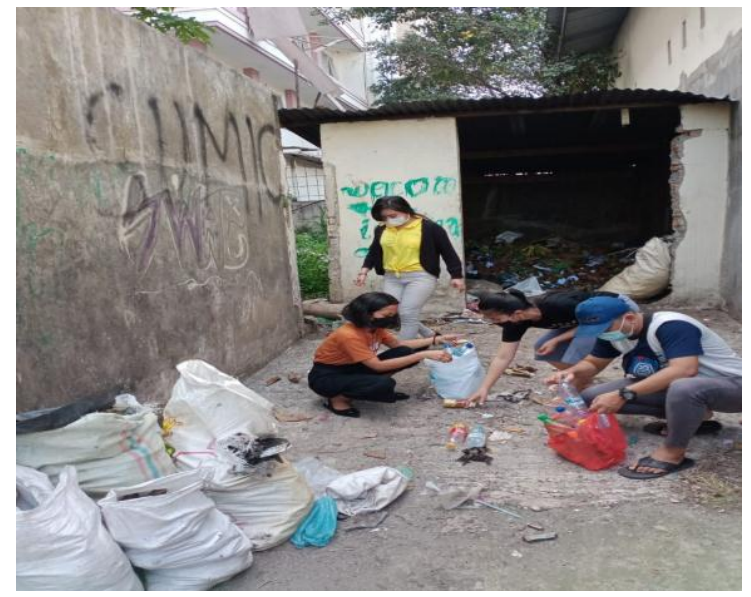

Gambar 1. Pengumpulan Sampah

(Sumber : Limbah Plastik FKIP UDA)

Sesi kedua adalah praktikum pembuatan ToSaPlas, setelah sampah botol mineral terkumpul, ketua dan anggota kelompok bekerja sama dalam menyediakan alat dan bahan yang dibutuhkan, mengerjakan setiap langkahlangkah pembuatan dengan benar hingga terbentuk ToSaPlas. ToSaPlas yang dibuat adalah sebanyak 2, satu untuk organik dan satu lagi untuk non organik, sesi ini dilaksanakan selama 3 minggu di rumah ketua kelompok, dan juga dilakukan dokumentasi. Proses praktikum pembuatan ToSaPlas diperlihatkan pada gambar 2, sedangkan hasilnya diperlihatkan pada gambar 3;

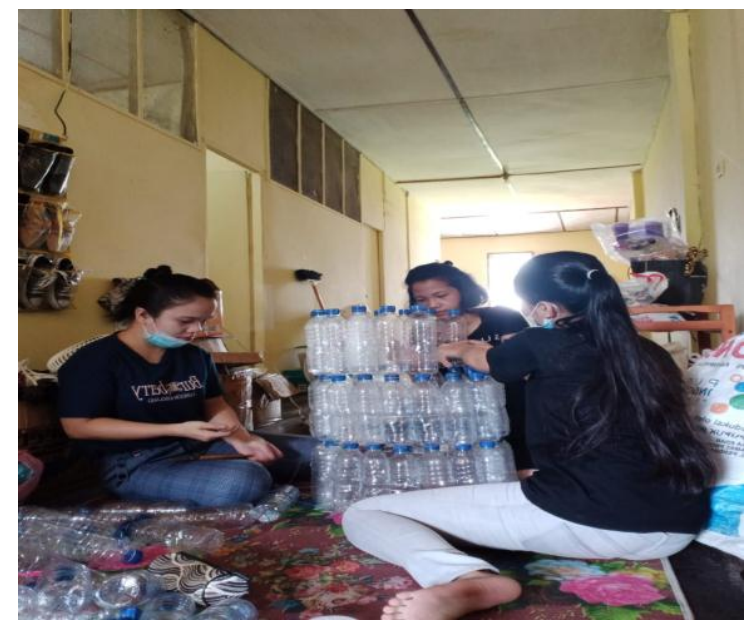

Gambar 2. Proses pembuatan ToSaPlas (Sumber: Limbah Plastik FKIP UDA)

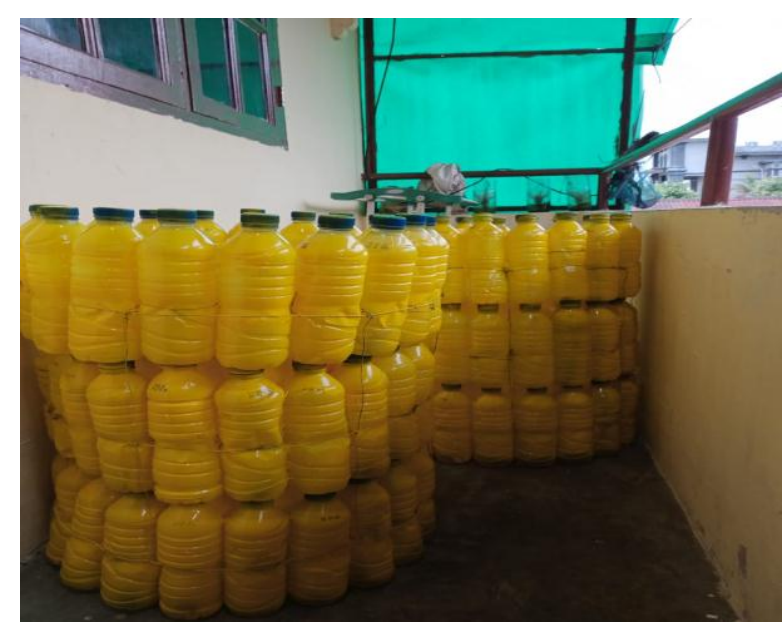

Gambar 3. Hasil ToSaPlas

(Sumber: Limbah Plastik FKIP UDA)

Peserta dari penelitian ini hanya ketua dan anggota kelompok, antusias dan kerja sama terjalin dengan baik dari persiapan hingga implementasi. Harapan setelah penelitian ini, mahasiswa FKIP UDA mendapat gambaran mengenai sumber ide kreatif yang bisa dikembangkan dari sampah plastik. Ada juga upaya untuk menyelamatkan lingkungan. Bahkan ide kreatif ini dapat dikembangkan untuk jiwa wirausaha bidang daur ulang sampah plastik dan menciptakan lapangan kerja baru bagi masyarakat, mengurangi kerusakan lingkungan akibat sampah plastik.

\section{SIMPULAN}

Adapun kesimpulan dari penelitian ini ialah seperti berikut di bawah ini :

1. Kegiatan penelitian ini mampu memberi pengetahuan dan pemahaman tentang pemanfaatan kembali limbah plastik dalam meminimalisir dampak dari permasalahan yang timbulkan oleh sampah.

2. Pengolahan sampah plastik dapat menciptakan benda yang lebih berguna seperti kerajinan tangan, dan diperlakukan sebagai barang yang layak 
untuk digunakan kembali. Kerajinan tangan yang bisa dibuat adalah tempat sampah plastik asli (ToSAPlas).

3. Mahasiswa FKIP UDA termasuk tim peneliti mendapat ide kreatif dalam mengelola kembali sampah yang dapat dikembangkan menjadi modal ilmu dalam berwirausaha serta dapat membuka lapangan pekerjaan baru bagi masyarakat.

\section{DAFTAR PUSTAKA}

Hakim, A. 2016. Landasan Teori Tentang Lingkungan. Dalam. http://eprints.walisongo.ac.id/6841/3 /BAB\%20II.pdf. Diakses pada 15 April 2021.

Istiqomah, Ani Alfi Noor. 2019. Tinjauan Pustaka Tentang Sampah. Dalam http://eprints.poltekkesjogja.ac.id/87 0/4/4\%20chapter\%202.pdf. Diakses pada 15 April 2021.

Jogloabang. 2019. UU 18 Tahun 2008 Tentang Pengelolaan Sampah. Dalam https://www.jogloabang.com/pustaka /uu-18-2008-pengelolaan-sampah.

Diakses pada 15 April 2021.

Priatna, Laely, Wahyu Hariadi dan Elly Kristiani (2019, November). Pengelolaan Sampah Di Tempat Pembuangan Akhir (Tpa) Gunung Tugel, Desa Kedungrandu, Kecamatan Patikraja, Kabupaten Banyumas.494-501.

Sendari, Anugerah Ayu. 2019. Kerajinan Tangan dari Botol Aqua Plastik dan Cara Pembuatannya. Dalam https : // m. liputan6. com/ citizen6/ read/ 3922294/kerajinan-tangan-daribotol-aqua-bekas-dan-carapembuatannya. Diakses pada 15 April 2021.

Sunaryo,Busori,Pratiwi Rini Susanti dan Agus Irkham (2011, Juli). Dampak
Program Pengelolaan Sampah Berbasis Masyarakat Sebagai Salah Satu Program Corporate Social Responsibility Badak Lng Terhadap Pembentukan Budaya Hijau (Green Culture) Pada Masyarakat Kota Bontang.46-54.

Suryani, Anih Sri (2014, Juni). Peran Bank Sampah Dalam Efektivitas Pengelolaan Sampah (Studi Kasus Bank Sampah Malang).71-84.

Wikipedia. 2016. Tempat Sampah. Dalam https://id.wikipedia.org/wiki/Tempat _ sampah. Diakses pada 15 April 2021.

Wulandari,DA. 2020. Tinjauan Pustaka Pengelolaan Sampah. Dalam http://eprints.poltekkesjogja.ac.id/37 23/4/Chapter\%202.pdf. Diakses pada 15 April 2021. 